\title{
BEHAVIOR AND DESIGN OF ALUMINUM ALLOY STRUCTURAL MEMBERS
}

\author{
Ji-Hua $\mathrm{Zhu}^{1}$ and Ben Young ${ }^{2, *}$ \\ ${ }^{I}$ Shenzhen Key Lab on Durability of Civil Engineering, College of Civil Engineering, ShenZhen University, \\ ShenZhen, PRChina. (zhujh@szu.edu.cn) \\ ${ }^{2}$ Department of Civil Engineering, The University of Hong Kong, Pokfulam Road, Hong Kong \\ *(Corresponding author: E-mail: young@hku.hk)
}

\begin{abstract}
This paper summarizes recent research on aluminum alloy structural members. The research program formed the basis of the $\mathrm{PhD}$ thesis of the first author. The behavior of aluminum alloy structural members was investigated experimentally and numerically. Tests were conducted on aluminum alloy columns, beams and beam-columns of square, rectangular and circular hollow sections. Numerical investigation was performed on fixed-ended aluminum alloy tubular columns with and without transverse welds at the ends of the columns. The effects of transverse welds on aluminum alloy columns were also investigated. The experimental and numerical results were compared with the design strengths calculated using the current American, Australian/New Zealand and European specifications for aluminum structures. In addition, the direct strength method, which was developed for cold-formed carbon steel members, was used in this study for aluminum alloy columns. Furthermore, design rules modified from the direct strength method were proposed. It is shown that the proposed design rules accurately predicted the ultimate strengths of aluminum non-welded and welded columns. The reliability of the current and proposed design rules for aluminum columns was evaluated using reliability analysis.
\end{abstract}

Keywords: Aluminum alloys; beams, beam-columns, buckling; columns; experimental investigation; heat-affected zone; numerical investigation; structural design; transverse welds

\begin{tabular}{|ll|}
\hline Nomenclature & \\
$A$ & $=$ gross cross-section area; \\
$B$ & $=$ overall width of SHS and RHS; \\
$D$ & $=$ overall diameter of CHS; \\
DL & $=$ plate width or depth; \\
$d$ & $=$ Young's modulus; \\
$E$ & $=$ axial shortening; \\
$e$ & $=$ measured loading eccentricity; \\
$e_{0}$ & $=$ finite element analysis; \\
FEA & $=$ material yield strength; \\
$f_{\mathrm{y}}$ & $=$ non-welded material yield strength; \\
$f_{\mathrm{y}-\mathrm{nw}}$ & $=$ overall depth of SHS and RHS; \\
$H$ & $=$ live load; \\
$L$ & $=$ column effective length; \\
$\mathrm{LL}$ & $=$ moment; \\
$l_{e}$ & $=$ end moment; \\
$M$ & $=$ maximum inelastic moment; \\
$M_{\text {end }}$ & $=$ ultimate moments; \\
$M_{m i}$ & $=$ axial load; \\
$M_{u}$ & $=$ critical elastic buckling load in flexural buckling, $\pi^{2} E A /\left(l_{e} / r\right)^{2} ;$ \\
$N$ & $=$ critical elastic local column buckling load; \\
$P_{\text {cre }}$ & $=$ column design strength calculated using the direct strength method; \\
$P_{\mathrm{crl}}$ & $=$ non-welded column design strength calculated using the modified direct \\
$P_{\mathrm{DSM}}$ & strength method; \\
$P_{\mathrm{DSM}-\mathrm{NW}}$ &
\end{tabular}




\begin{tabular}{|l|l|}
\hline$P_{\mathrm{ne}}$ & $=$ nominal axial strength for flexural buckling; \\
$P_{u}$ & $=$ column strength; \\
$P_{\mathrm{y}}$ & $=$ yield strength of the section $\left(f_{\mathrm{y}} A\right) ;$ \\
$P_{\mathrm{y}-\mathrm{nw}}$ & yield strength of the section calculated using the non-welded material \\
& properties $\left(f_{\mathrm{y}-\mathrm{nw}} A\right) ;$ \\
$r$ & $=$ radius of gyration of gross cross-section about the minor $y$ - axis of buckling; \\
$t$ & $=$ thickness of section; \\
$z$ & $=$ reliability index; \\
$\beta$ & $=$ non-dimensional slenderness for flexural buckling; \\
$\lambda_{\mathrm{c}}$ & $=$ non-dimensional slenderness for interaction of local and flexural buckling; \\
$\lambda_{l}$ & $=$ heat-affected zone (HAZ) softening factor specified in the Eurocode $9 ;$ \\
$\rho_{\text {haz-EC9 }}$ & $=$ heat-affected zone (HAZ) softening factor obtained from the FEA; \\
$\rho_{\text {haz-FEA }}$ & $=$ resistance factor. \\
$\rho_{\text {haz-P }}$ &
\end{tabular}

\section{INTRODUCTION}

Aluminum tubular members are used in curtain walls, space structures and other structural applications. The aluminum tubular members are normally manufactured by heat-treated aluminum alloys, because heat-treated alloys have notably higher yield stress than non-heat-treated alloys. The advantages of using aluminum alloys as a structural material are the high strength-to-weight ratio, lightness, corrosion resistance and ease of production.

There are drawbacks of using aluminum alloys for structural applications, such as the low Young's modulus of aluminum that is roughly one third of steel and cause aluminum member to easily fail by buckling. The American Aluminum Design Manual (AA) [1], Australian/New Zealand Standard (AS/NZS) [2] and European Code (EC9) [3] provide design rules for aluminum structural members. Previous research of aluminum structural members was mainly focused on the ultimate strength of compact (non-slender) sections. However, the use of aluminum thin-walled sections has increase in recent years. Hence, it is necessary to investigate the behavior and design of aluminum columns, beams and beam-columns of slender sections.

In addition, when heat-treated aluminum alloys are welded, the heat generated from the welding reduces the material strength significantly in a localized region, and this is known as the heat-affected zone (HAZ) softening. It is assumed that the heat-affected zone extends 1 inch $(25.4$ $\mathrm{mm}$ ) to each side of the centre of a weld [1]. In the case of the 6000 Series alloys, the heat generated from the welding can locally reduce the parent metal strength by nearly half [4]. The effects of welding on the strength and behavior of aluminum structural members depend on the direction, location and number of welds. In aluminum structures, welds are divided into two types, namely (1) transverse welds; (2) longitudinal welds, for the purpose of divining their influence on member strength. Generally, transverse welds are often used in connections, whereas longitudinal welds are used for the fabrication of built-up members [5]. The current American Aluminum Design Manual [1], Australian/New Zealand Standard [2] and European Code [3] for aluminum structures provide design rules for structural members containing transverse and longitudinal welds. The behavior of non-welded and longitudinally welded columns have been investigated. Summaries of these research can be found in Mazzolani [4] and Sharp [6]. However, there are not many research being carried out on the behavior of aluminum columns containing transverses welds. Some numerical investigations have been mentioned by Mazzolani [4], whereas test data have been reported by Brungraber and Clark [7]. 
The purpose of this paper is to briefly summarize the experimental and numerical investigations as well as design of aluminum alloy structural members. The research program formed the basis of the $\mathrm{PhD}$ thesis [8] of the first author. The research findings have been published recently in international journals, and reference is made to these publications for further details. Table 1 summarizes the number of specimens investigated experimentally and numerically as well as the reference of the investigation.

Table 1. Data of Aluminum Alloy Structural Members

\begin{tabular}{|l|c|c|}
\hline Type & No. of specimens & References \\
\hline Fix-ended columns (experimental) & 70 & {$[9,10]$} \\
\hline Fix-ended columns (numerical) & 248 & {$[8,15]$} \\
\hline Beams and beam-columns (experimental) & 50 & {$[11,12]$} \\
\hline
\end{tabular}

\section{EXPERIMENTAL INVESTIGATION}

\subsection{Column Tests}

A series of tests described by Zhu and Young [9, 10] provide experimental ultimate loads and failure modes of aluminum columns with and without transverse welds at the ends of the columns. The tests were performed on square (SHS), rectangular (RHS) and circular (CHS) hollow section aluminum columns. The test specimens were fabricated by extrusion using 6063-T5 and 6061-T6 heat-treated aluminum alloys. Each specimen was cut to a specified length ranging from 300 to $3000 \mathrm{~mm}$. The test program included 50 fixed-ended columns with both ends welded to aluminum end plates, and 20 fixed-ended columns without the welding of end plates. In this paper, the term "welded column" refers to a specimen with transverse welds at the ends of the column to the aluminum end plates. The term "non-welded column" refers to a specimen without transverse welds at the ends of the column, but still using aluminum end plates in the test. Therefore, the testing conditions of the welded and non-welded columns are identical, other than the absence of welding in the non-welded columns. The specimens were separated into nine series for different type of aluminum alloy and cross-section geometry, as shown in Tables 2 and 3 using the symbols illustrated in Figure 1.

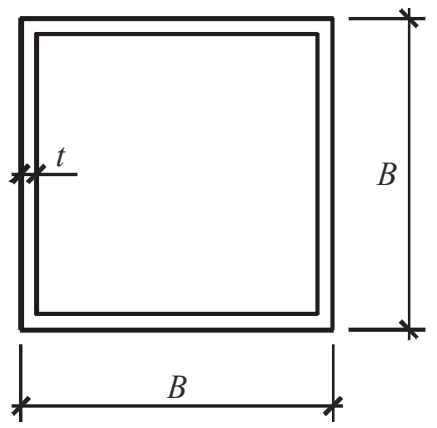

(a) SHS

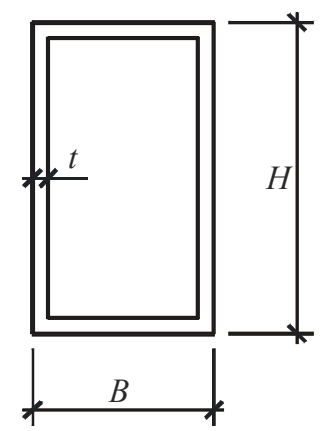

(b) RHS

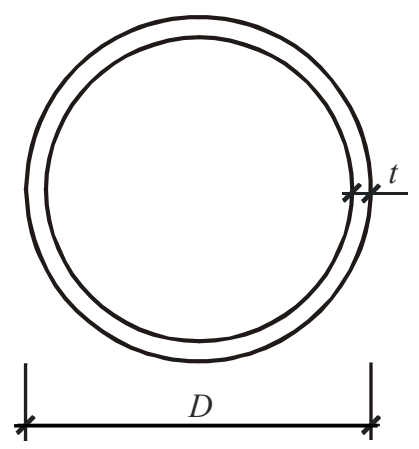

(c) $\mathrm{CHS}$

Figure 1. Definition of Symbols 
Table 2. SHS and RHS Column Test Series

\begin{tabular}{|c|c|c|}
\hline Test series & Type of material & $\begin{array}{c}\text { Dimension } \\
H \times B \times t \\
(\mathrm{~mm})\end{array}$ \\
\hline N-S1 & $6063-\mathrm{T} 5$ & $44 \times 44 \times 1.1$ \\
\hline N-R1 & $6063-\mathrm{T} 5$ & $100 \times 44 \times 1.2$ \\
\hline N-R2 & $6063-\mathrm{T} 5$ & $100 \times 44 \times 3.0$ \\
\hline H-S1 & $6061-\mathrm{T} 6$ & $44 \times 44 \times 1.1$ \\
\hline H-R1 & $6061-\mathrm{T} 6$ & $100 \times 44 \times 1.2$ \\
\hline H-R2 & $6061-\mathrm{T} 6$ & $100 \times 44 \times 3.0$ \\
\hline
\end{tabular}

Table 3. CHS Column Test Series

\begin{tabular}{|c|c|c|}
\hline Test series & Type of material & $\begin{array}{c}\text { Dimension } \\
D \times t \\
(\mathrm{~mm})\end{array}$ \\
\hline $\mathrm{N}-\mathrm{C} 1$ & $6063-\mathrm{T} 5$ & $50 \times 1.6$ \\
\hline $\mathrm{N}-\mathrm{C} 2$ & $6063-\mathrm{T} 5$ & $50 \times 3.0$ \\
\hline $\mathrm{H}-\mathrm{C} 1$ & $6061-\mathrm{T} 6$ & $50 \times 1.6$ \\
\hline $\mathrm{H}-\mathrm{C} 2$ & $6061-\mathrm{T} 6$ & $50 \times 3.0$ \\
\hline
\end{tabular}

Longitudinal tensile coupon tests were performed to determine the non-welded material properties. The coupon specimens included flat coupons taken from the SHS and RHS, and curved face coupons taken from the CHS. Longitudinal compression coupon tests were also performed on coupon specimens taken from the RHS. Two types of welded longitudinal tensile coupons with gauge length of either 25 or $250 \mathrm{~mm}$ were tested to determine the welded material properties. The measured material properties determined from the non-welded and welded coupon tests are detailed in Zhu and Young $[9,10]$.

A typical column test is shown in Figure 2. A servo-controlled hydraulic testing machine was used to apply compressive axial force to the specimen. The specimens were tested between fixed ends. Details of the test rig are given in Zhu and Young [9]. The observed failure modes include local buckling, flexural buckling, as well as interaction of local and overall buckling. Some welded columns failed by material yielding at the heat-affected zone (HAZ) as detailed in Zhu and Young $[9,10]$. Figure 2 shows the specimen failed by local buckling. Initial local and overall geometric imperfections were measured on the test specimens prior to testing, as detailed in Zhu and Young [9, 10]. A typical measured local imperfection profiles for the RHS of Series H-R1 is shown in Figure 3. The column strengths, failure modes and the comparison of test strengths with design strengths are detailed in Zhu and Young $[9,10]$. 


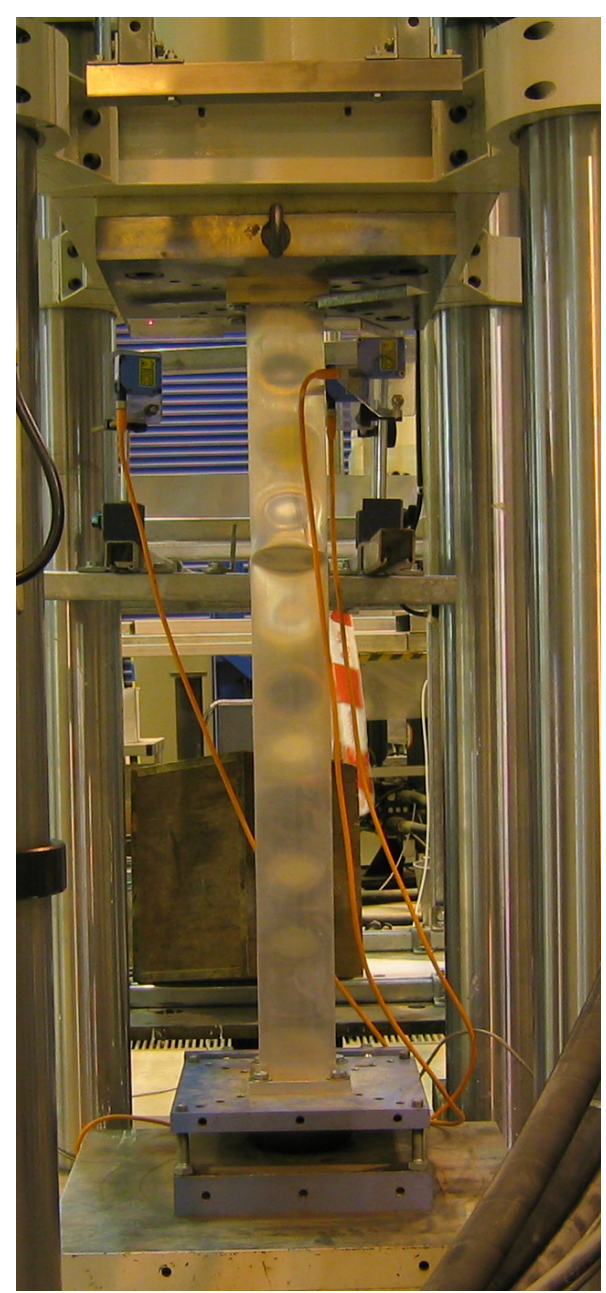

Figure 2. Column Specimen Failed by Local Buckling

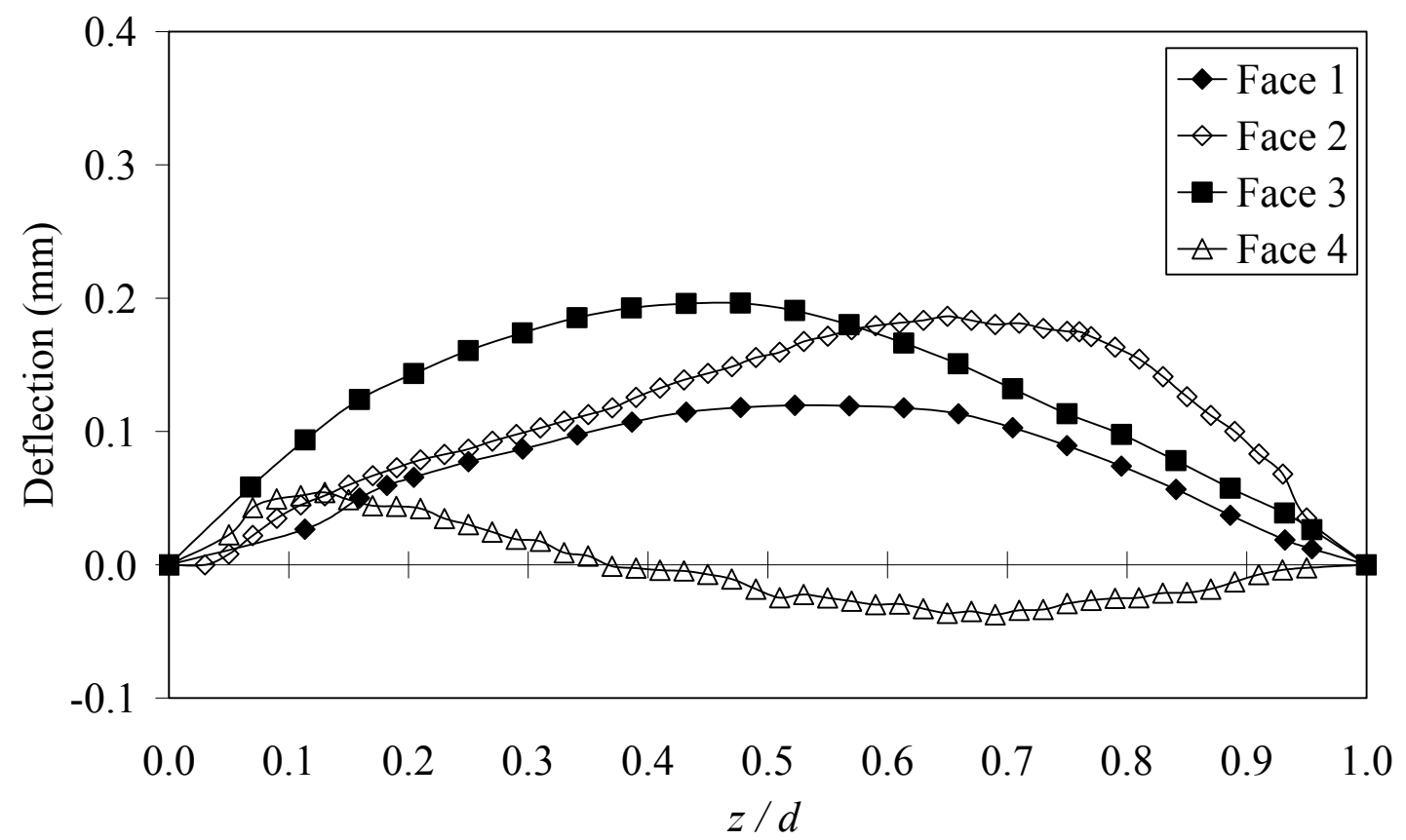

Figure 3. Measured Local Geometric Imperfection Profiles for RHS of Series H-R1 


\subsection{Beam Tests}

Tests on aluminum alloy beams and beam-columns have been conducted by Zhu and Young [11, 12]. Six beam tests were performed on SHS, RHS and CHS specimens of aluminum alloy 6061-T6, as shown in Table 4. The bending capacity of the test specimens was used to obtain the complete experimental interaction curves of aluminum alloy beam-columns. Hence, the beam specimens were tested under pure bending condition. The beam specimens were cut from those specimens belonged to the same batch of specimens as the column and beam-column tests. The length of the specimens was chosen such that the section bending capacity could be obtained.

Table 4. Beam Test Results

\begin{tabular}{|l|c|c|c|c|}
\hline Specimen & $\begin{array}{c}\text { Type of } \\
\text { material }\end{array}$ & \multirow{2}{*}{$\begin{array}{c}\text { Dimension } \\
(\mathrm{mm})\end{array}$} & \multicolumn{2}{|c|}{ Test results } \\
\cline { 3 - 5 } & $6061-\mathrm{T} 6$ & $44 \times 44 \times 1.1$ & Failure Mode & $M_{u}(\mathrm{kNmm})$ \\
\hline S1-PB & $6061-\mathrm{T} 6$ & $100 \times 44 \times 1.2$ & $\mathrm{~L}$ & 814.5 \\
\hline R1-PB & $6061-\mathrm{T} 6$ & $100 \times 44 \times 3.0$ & $\mathrm{~F}$ & 34017.5 \\
\hline R2-PB & $6061-\mathrm{T} 6$ & $100 \times 44 \times 3.0$ & $\mathrm{~F}$ & 3450.0 \\
\hline R2-PB\# & $6061-\mathrm{T} 6$ & $50 \times 1.6$ & $\mathrm{~F}$ & 1152.0 \\
\hline C1-PB & $5061-\mathrm{T} 6$ & $50 \times 3.0$ & $\mathrm{~F}$ & 2138.0 \\
\hline C2-PB & 60.0 & & \\
\hline
\end{tabular}

Note: $\#=$ Repeated test; $\mathrm{F}=$ Flexural buckling; $\mathrm{L}=$ Local buckling.

A typical beam test is shown in Figure 4. The test rig and test operation are detailed in Zhu and Young $[11,12]$. The experimental ultimate moments $\left(M_{u}\right)$ of the beam specimens are shown in Table 4. The $M_{u}$ was obtained using half of the ultimate applied load from the actuator multiplied by the lever arm (distance from the support to the loading point) of the specimens. The mass of the spread beam, half round, roller and bearing plates were included in the calculation of the ultimate moments. Specimens S1-PB and R1-PB failed by local buckling, whereas specimens R2-PB, R2-PB\#, C1-PB and C2-PB failed by flexural buckling (material yielding due to large deflection). Figure 4 shows the failure of specimen R2-PB.

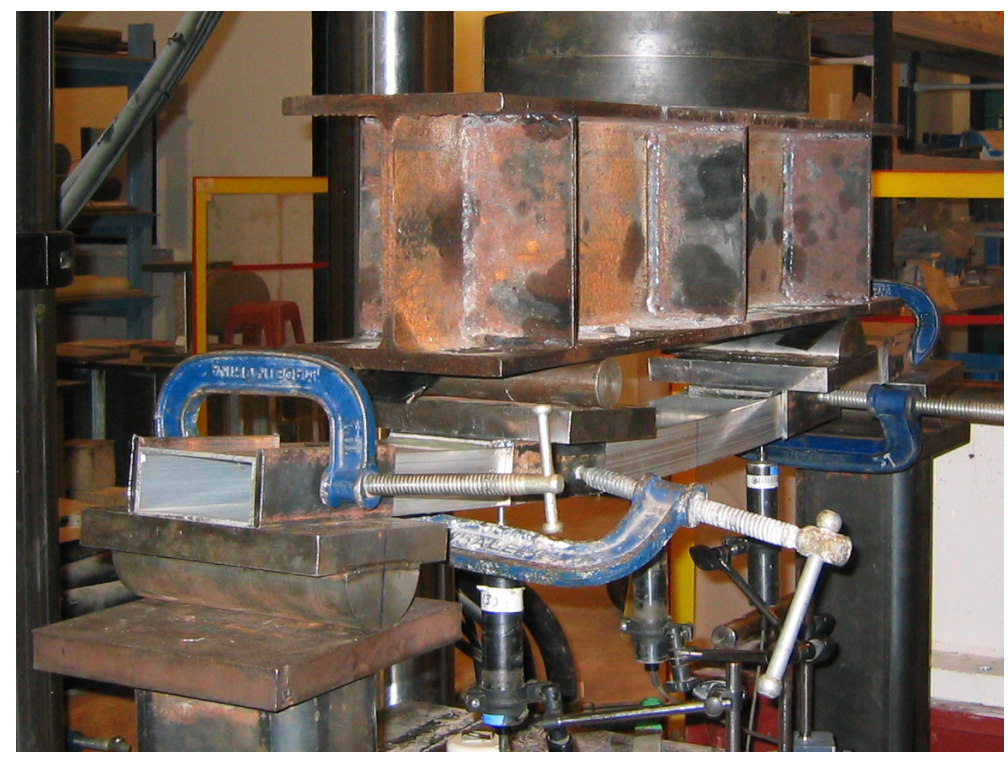

Figure 4. Flexural Buckling of Beam Specimen R2-PB 


\subsection{Beam-column Tests}

The beam-column tests were performed on aluminum alloy square (SHS), rectangular (RHS) and circular (CHS) hollow sections, as reported by Zhu and Young $[11,12]$. The test specimens were manufactured by extrusion using 6061-T6 heat-treated aluminum alloy. The specimens were cut from those specimens belonged to the same batch of specimens as the column and beam tests. The beam-column specimens were separated into ten series of different cross-section geometry and specimen length, as shown in Tables 5 and 6 using the symbols illustrated in Figure 1.

Table 5. SHS and RHS Beam-column Test Series

\begin{tabular}{|l|c|c|c|}
\hline Test series & $\begin{array}{c}\text { Type of } \\
\text { material }\end{array}$ & $\begin{array}{c}\text { Length } \\
L \\
(\mathrm{~mm})\end{array}$ & $\begin{array}{c}\text { Dimension } \\
H \times B \times t \\
(\mathrm{~mm})\end{array}$ \\
\hline S1L600 & $6061-\mathrm{T} 6$ & 600 & $44 \times 44 \times 1.1$ \\
\hline S1L1200 & $6061-\mathrm{T} 6$ & 1200 & $44 \times 44 \times 1.1$ \\
\hline R1L600 & $6061-\mathrm{T} 6$ & 600 & $100 \times 44 \times 1.2$ \\
\hline R1L1200 & $6061-\mathrm{T} 6$ & 1200 & $100 \times 44 \times 1.2$ \\
\hline R2L600 & $6061-\mathrm{T} 6$ & 600 & $100 \times 44 \times 3.0$ \\
\hline R2L1200 & $6061-\mathrm{T} 6$ & 1200 & $100 \times 44 \times 3.0$ \\
\hline
\end{tabular}

Table 6. CHS Beam-column Test Series

\begin{tabular}{|l|c|c|c|}
\hline Test series & $\begin{array}{c}\text { Type of } \\
\text { material }\end{array}$ & $\begin{array}{c}\text { Length } \\
L \\
(\mathrm{~mm})\end{array}$ & $\begin{array}{c}\text { Dimension } \\
D \times t \\
(\mathrm{~mm})\end{array}$ \\
\hline C1L500 & $6061-\mathrm{T} 6$ & 500 & $50 \times 1.6$ \\
\hline C1L1000 & $6061-\mathrm{T} 6$ & 1000 & $50 \times 1.6$ \\
\hline C2L500 & $6061-\mathrm{T} 6$ & 500 & $50 \times 3.0$ \\
\hline C2L1000 & $6061-\mathrm{T} 6$ & 1000 & $50 \times 3.0$ \\
\hline
\end{tabular}

For the SHS and RHS, the test program included 27 beam-columns compressed between pinned ends at different eccentricities in order to obtain an interaction curve for each series of test. Each test series contained one specimen tested with an eccentricity near zero (concentrically loaded) to determine the axial capacity. Each specimen was cut to a specified length of either 600 or $1200 \mathrm{~mm}$. For the CHS, the test program included 17 beam-column specimens. Similar to the SHS and RHS beam-column test program, each test series contained one specimen tested with an eccentricity near zero to determine the axial capacity. Each specimen was cut to a specified length of either 500 or $1000 \mathrm{~mm}$. Both ends of the specimens were welded to aluminum end plates to connect the specimens to the pinned bearings.

Figure 5 shows a typical beam-column test. The test rig and test operation are detailed in Zhu and Young $[11,12]$. A computer program has been written for this study to calculate the measured loading eccentricity $\left(e_{0}\right)$ of the beam-column specimens during the initial part of the tests by measuring the applied load, longitudinal strains and overall deflection at mid-length about the bending axis of the specimens. The measured loading eccentricity $\left(e_{0}\right)$ was calculated for each load increment during the initial loading and the average value is adopted for each beam-column specimen, as shown in Zhu and Young [11, 12]. Initial overall geometric imperfections were measured for the beam-column specimens of 1200 and $1000 \mathrm{~mm}$ in length prior to testing. 
The plot of axial load $(N)$ versus moments for Series C2L1000 is shown in Figure 6, where the curves with thick line represent the axial load versus the maximum inelastic moment $\left(M_{m i}\right)$, and the curves with thinner line represent the axial load versus the end moment $\left(M_{\text {end }}\right)$. The ultimate points for the axial load versus maximum inelastic moment curves are also shown in Figure 6 . The observed failure modes include local buckling, flexural buckling, as well as interaction of local and overall flexural buckling. Figure 5 shows the specimen failed by flexural buckling. It should be noted that some short specimens tested with small eccentricity failed by material yielding at the heat-affected zone (HAZ).

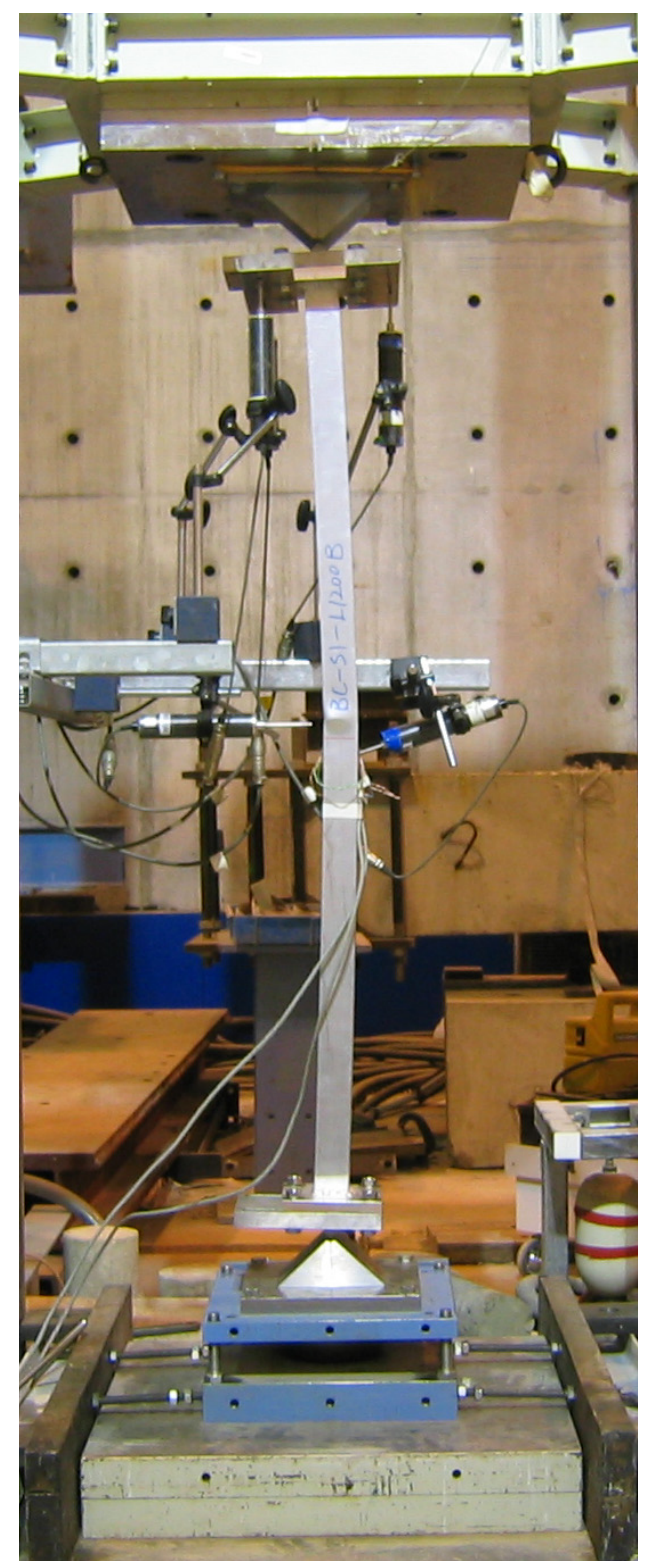

Figure 5. Beam-column Specimen Failed by Flexural Buckling 


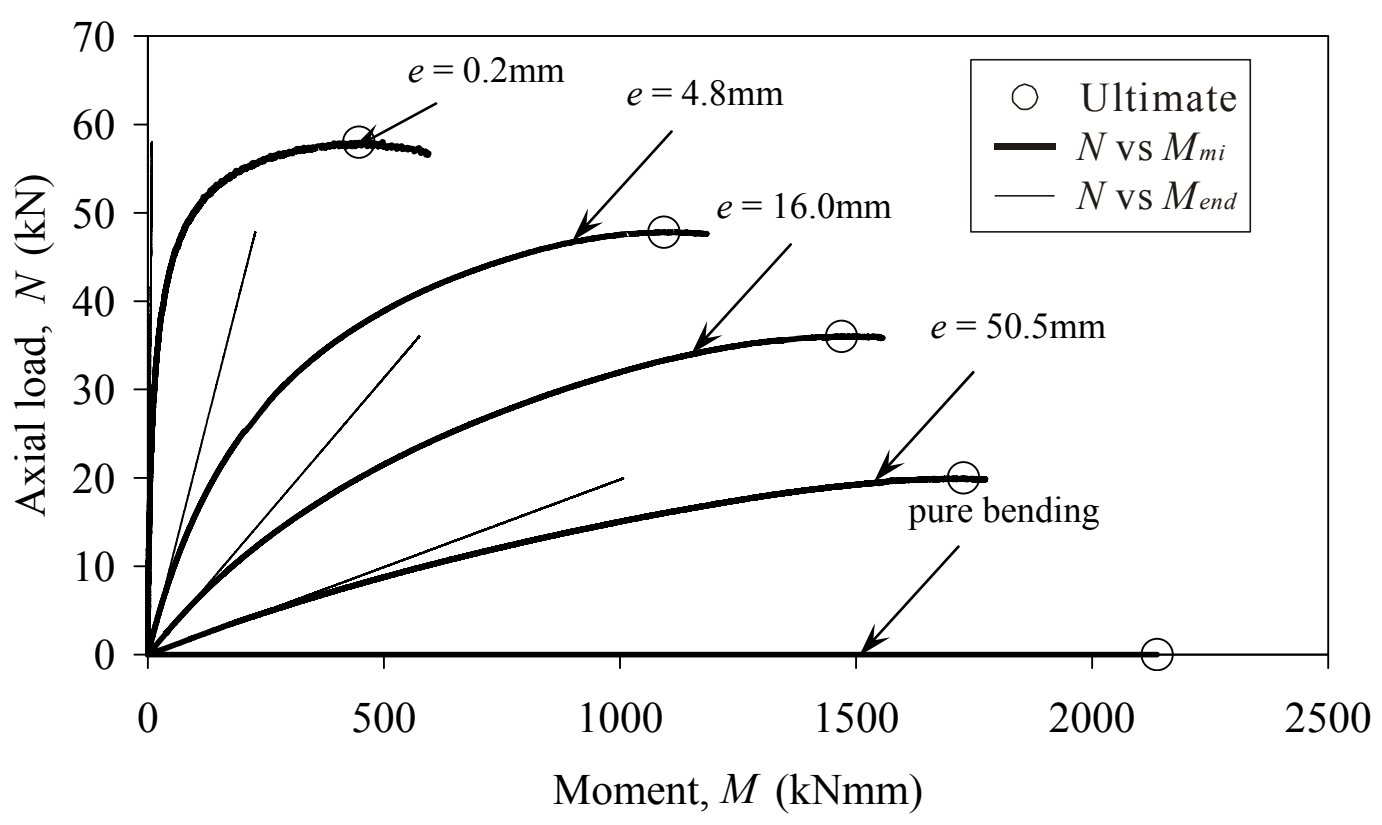

Figure 6. Axial Load versus Moment for Beam-column Series C2L1000

\section{NUMERICAL INVESTIGATION}

The finite element program ABAQUS [13] was used in the analysis for the simulation of aluminum alloy fixed-ended columns $[9,10]$. An accurate and reliable non-linear finite element model for aluminum non-welded and welded columns has been presented by Zhu and Young [14, 15]. The development of the finite element model (FEM) is detailed in Zhu and Young [14]. In the FEM, the measured cross-section dimensions, material properties and initial geometric imperfections of the test specimens were modeled. The fixed-ended boundary condition was modeled by restraining all the degrees of freedom of the nodes at both ends of the column, except for the translational degree of freedom in the axial direction at one end of the column. The nodes other than the two ends were free to translate and rotate in any directions. The material non-linearity was included in the FEM by specifying the true values of stresses and strains. The plasticity of the material was simulated by a mathematical model, known as the incremental plasticity model, in which the true stresses and true plastic strains were calculated in accordance with ABAQUS [13]. The geometric imperfections were included in the FEM by using the Eigenvalue analyses. The displacement control loading method was used in the finite element analysis (FEA) that was identical to the loading method used in the column tests. The S4R general-purpose shell elements were used in the FEM. The welded columns were modeled by dividing the columns into different portions along the column length. Therefore, the heat-affected zone (HAZ) softening at both ends of the columns were simulated.

The FEM closely predicted the experimental ultimate loads and failure modes of the tested aluminum columns, as detailed in Zhu and Young [14]. Figure 7 shows the comparison of the load-shortening curves obtained from the test and predicted by the FEA for the non-welded column specimen H-R2-NW-L1000. Hence, the model was used for an extensive parametric study. The parametric study included 120 SHS and RHS columns that consisted of 24 series, as well as 80 CHS columns that consisted of 16 series. Each series contained 5 specimens with column lengths of $500,1200,2000,2700$ and $3500 \mathrm{~mm}$. The column strengths obtained from the parametric study are detailed in Zhu and Young [15]. 


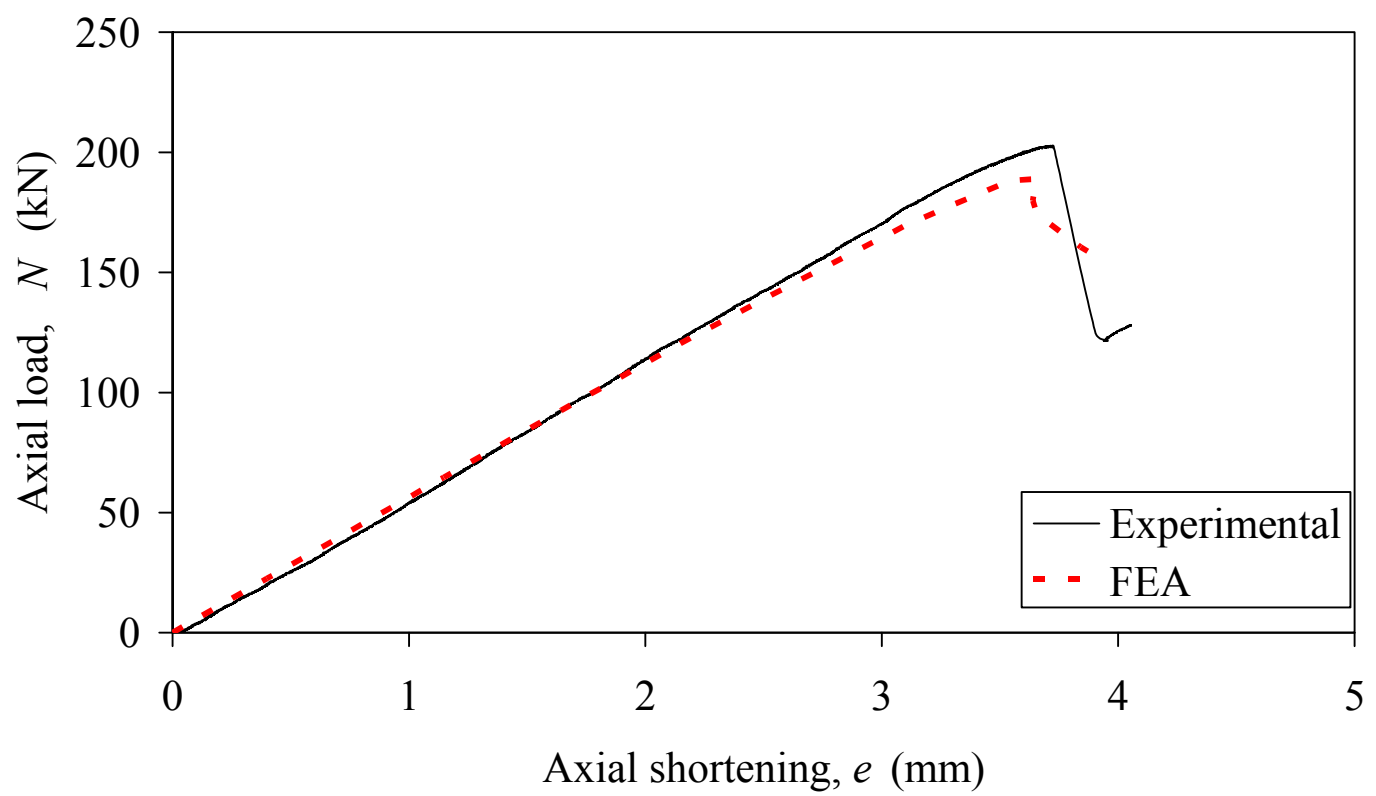

Figure 7. Comparison of Experimental and FEA Axial load-shortening Curves for Specimen H-R2-NW-L1000

\section{EFFECTS OF TRANSVERSE WELDS ON ALUMINUM ALLOY COLUMNS}

Research on aluminum columns containing transverse welds are summarized by Mazzolani [4] and Sharp [6]. However, previous research was mainly focused on the effects of transverse welds with respect to different column lengths. A numerical investigation described by Zhu and Young [16] is focused on the effects of transverse welds on aluminum alloy columns with respect to section slenderness.

The parametric study included 48 columns of six SHS and six CHS of different section thickness, as detailed in Zhu and Young [16]. Non-welded and welded columns of aluminum alloy 6063-T5 and 6061-T6 were modeled for each section. This study focused on the effects of transverse welds on column strengths with respect to section slenderness. Hence, the parametric study was performed on stub columns of $600 \mathrm{~mm}$ in length that generally followed the stub column length suggested by Galambos [17]. The heat-affected zone softening factor ( $\left.\rho_{\text {haz-FEA }}\right)$ obtained from the parametric study is detailed in Zhu and Young [16]. Figure 8 shows the $\rho_{\text {haz-FEA }}$ results plotted against the overall diameter-to-thickness ratio $(D / t)$ for the CHS columns. The value of the HAZ softening factor $\left(\rho_{\text {haz-FEA }}\right)$ obtained from the parametric study is clearly decreases as the value of $D / t$ increases for the CHS columns, as shown in Figure 8. The proposed heat-affected zone softening factor $\left(\rho_{\text {haz-P }}\right)$ for CHS is also shown in Figure 8. Details of the proposed equation are shown in Zhu and Young [16]. The HAZ softening factors obtained from the parametric study ( $\left.\rho_{\text {haz-FEA }}\right)$ are compared with the values $\left(\rho_{\text {haz-EC9}}\right)$ specified in the EC9 Code for the SHS and CHS specimens, as described by Zhu and Young [16]. 


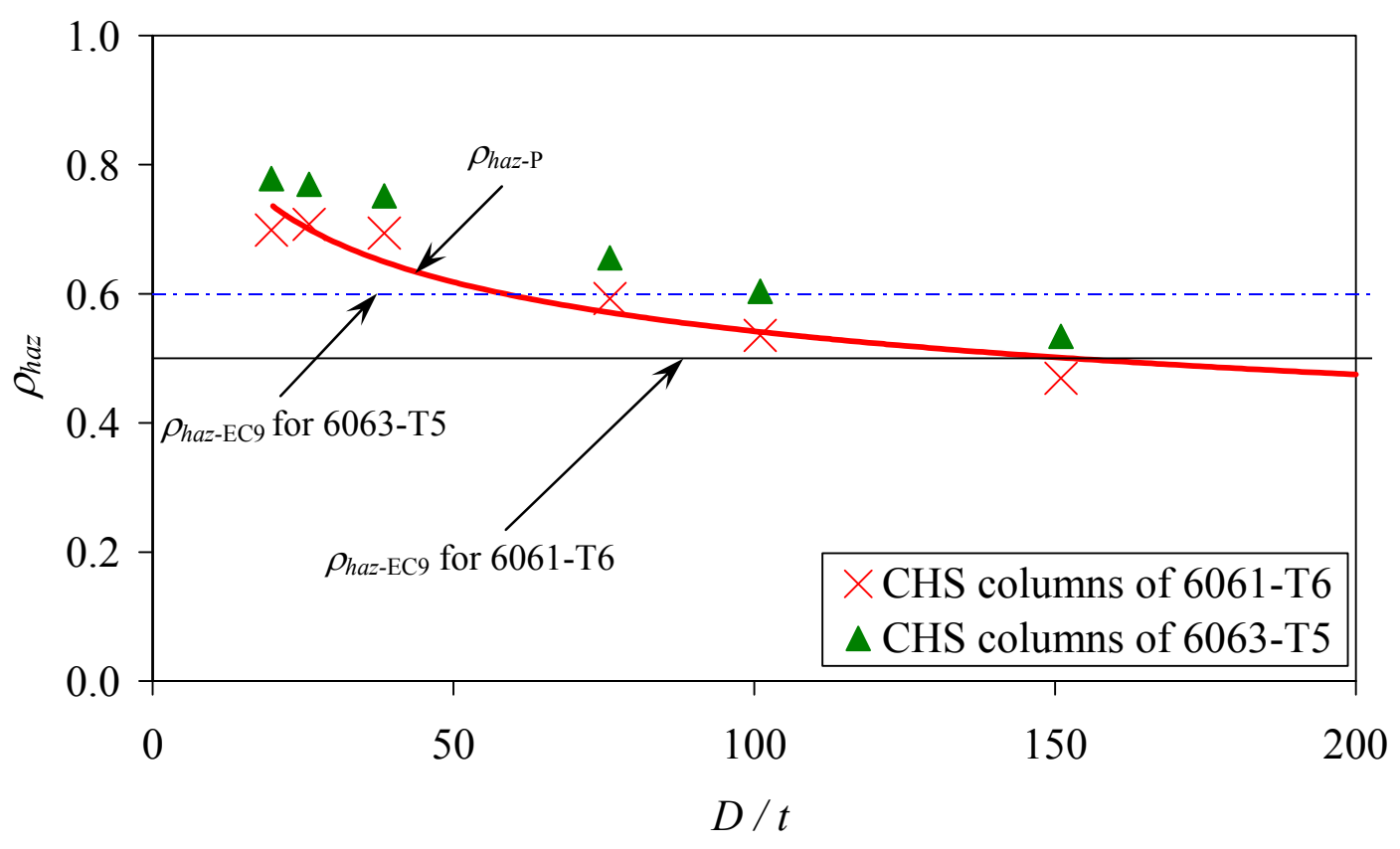

Figure 8. Heat-affected Zone Softening Factor of CHS Columns

\section{DESIGN RECOMMENDATIONS}

The fixed-ended column strengths obtained from the experimental investigation [9, 10] and numerical investigation $[8,15]$ were compared with the design strengths calculated using the current American Aluminum Design Manual [1], Australian/New Zealand Standard [2] and European Code [3] for aluminum structures, as detailed in Zhu [8] and Zhu and Young [9, 10]. It is shown that these design rules are generally conservative for non-welded columns. It is also shown that these design rules are generally quite conservative for welded columns.

The direct strength method (DSM) that detailed in the North American Specification (NAS) [18, 19] for cold-formed steel structures was used for the design of aluminum alloy columns as described by Zhu and Young [15]. As summarized in the North American Specification for cold-formed steel structures, the column design rules of the direct strength method that considered the local and overall flexural buckling are shown in Eqs. (1) - (3). The values of 0.15 and 0.4 are the coefficient and exponent of the direct strength equation, respectively, that were calibrated against test data of concentrically loaded pin-ended cold-formed steel columns for certain cross sections and geometric limits.

$$
\begin{aligned}
& P_{\mathrm{DSM}}=\min \left(P_{\mathrm{ne}}, P_{\mathrm{n} l}\right) \\
& P_{\mathrm{ne}}= \begin{cases}\left(0.658^{\lambda_{\mathrm{c}}^{2}}\right) P_{\mathrm{y}} & \text { for } \lambda_{\mathrm{c}} \leq 1.5 \\
\left(\frac{0.877}{\lambda_{\mathrm{c}}^{2}}\right) P_{\mathrm{y}} & \text { for } \lambda_{\mathrm{c}}>1.5\end{cases}
\end{aligned}
$$


$P_{\mathrm{n} l}= \begin{cases}P_{\mathrm{ne}} & \text { for } \lambda_{l} \leq 0.776 \\ {\left[1-0.15\left(\frac{P_{\mathrm{cr} l}}{P_{\mathrm{ne}}}\right)^{0.4}\right]\left(\frac{P_{\mathrm{cr} l}}{P_{\mathrm{ne}}}\right)^{0.4} P_{\mathrm{ne}}} & \text { for } \lambda_{l}>0.776\end{cases}$

where $P_{\mathrm{y}}=f_{\mathrm{y}} A ; \quad \lambda_{\mathrm{c}}=\sqrt{P_{\mathrm{y}} / P_{\mathrm{cre}}} ; \quad \lambda_{l}=\sqrt{P_{\mathrm{ne}} / P_{\mathrm{cr} l}}$.

$A=$ Gross cross-section area;

$f_{\mathrm{y}}=$ Material yield strength which is the static $0.2 \%$ proof stress $\left(\sigma_{0.2}\right)$ using the non-welded material properties in this paper;

$P_{\text {cre }}=\pi^{2} E A /\left(l_{e} / r\right)^{2}$, critical elastic buckling load in flexural buckling for tubular columns;

$P_{\text {crl }}=$ Critical elastic local column buckling load;

$E=$ Young's modulus;

$l_{e}=$ Column effective length;

$r=$ Radius of gyration of gross cross-section about the minor $y$ - axis of buckling.

It should be noted that the direct strength method was developed based on open sections, such as simple lipped channel, lipped channel with web stiffeners, Zed section, hat section and rack upright section. In this study, square, rectangular and circular hollow sections are investigated. Therefore, the direct strength method for cold-formed carbon steel members was modified for aluminum alloy columns. The proposed design equations for aluminum alloy SHS and RHS columns without transverse welds at the ends of the columns (non-welded columns) are described in Zhu and Young [15] and shown as follows:

$P_{\mathrm{DSM}-\mathrm{NW}}=\min \left(P_{\mathrm{ne}}, P_{\mathrm{n} l}\right)$

$P_{\mathrm{ne}}= \begin{cases}\left(0.658^{\lambda_{\mathrm{c}}^{2}}\right) P_{\mathrm{y}-\mathrm{nw}} & \text { for } \lambda_{\mathrm{c}} \leq 1.5 \\ \left(\frac{0.877}{\lambda_{\mathrm{c}}^{2}}\right) P_{\mathrm{y}-\mathrm{nw}} & \text { for } \lambda_{\mathrm{c}}>1.5\end{cases}$

$P_{\mathrm{n} l}= \begin{cases}P_{\mathrm{ne}} & \text { for } \lambda_{l} \leq 0.713 \\ {\left[1-0.15\left(\frac{P_{\mathrm{cr} l}}{P_{\mathrm{ne}}}\right)^{0.3}\right]\left(\frac{P_{\mathrm{cr} l}}{P_{\mathrm{ne}}}\right)^{0.3} P_{\mathrm{ne}}} & \text { for } \lambda_{l}>0.713\end{cases}$

where $P_{\mathrm{y}-\mathrm{nw}}=f_{\mathrm{y}-\mathrm{nw}} A ; \quad \lambda_{\mathrm{c}}=\sqrt{P_{\mathrm{y}-\mathrm{nw}} / P_{\mathrm{cre}}} ; \quad \lambda_{l}=\sqrt{P_{\mathrm{ne}} / P_{\mathrm{cr} l}}$.

$f_{\mathrm{y}-\mathrm{nw}}=$ Non-welded material yield strength.

The design equations were verified against the numerical results [15] and the test results [9]. The proposed design Eqs. (4) - (6) for aluminum SHS and RHS non-welded columns require only small modifications to the current direct strength method for cold-formed steel members. In Eq. (3), the value of the exponent 0.4 was modified to 0.3 , and the non-dimensional slenderness $\left(\lambda_{l}\right)$ has been adjusted to 0.713 for a smooth transition of the elastic and inelastic buckling loads as shown in Eq. (6). As a result, the reliability index ( $\beta$ ) of 2.86 was obtained for the proposed design rules, which is closer to the target value of 2.5 compared with the reliability index $(\beta)$ of 3.07 for the current direct strength method, as shown in Figure 9. The load combination of 1.2DL (dead load) +1.6LL (live load) was used in calculating the reliability index as specified in the AA Specification [1]. The 
resistance factor $(\phi)$ of 0.85 was used in the calculation. The reliability analysis is detailed in Zhu and Young [15]. Figure 9 shows the comparison of FEA and experimental results of SHS and RHS non-welded columns against the current and modified direct strength curves plotted from Eq. (3) and Eq. (6), respectively. Generally, the results predicted using the current and modified direct strength methods compared reasonably well with the FEA and experimental results. However, the modified direct strength method provided a reliability index closer to the target value compared with the current direct strength method.

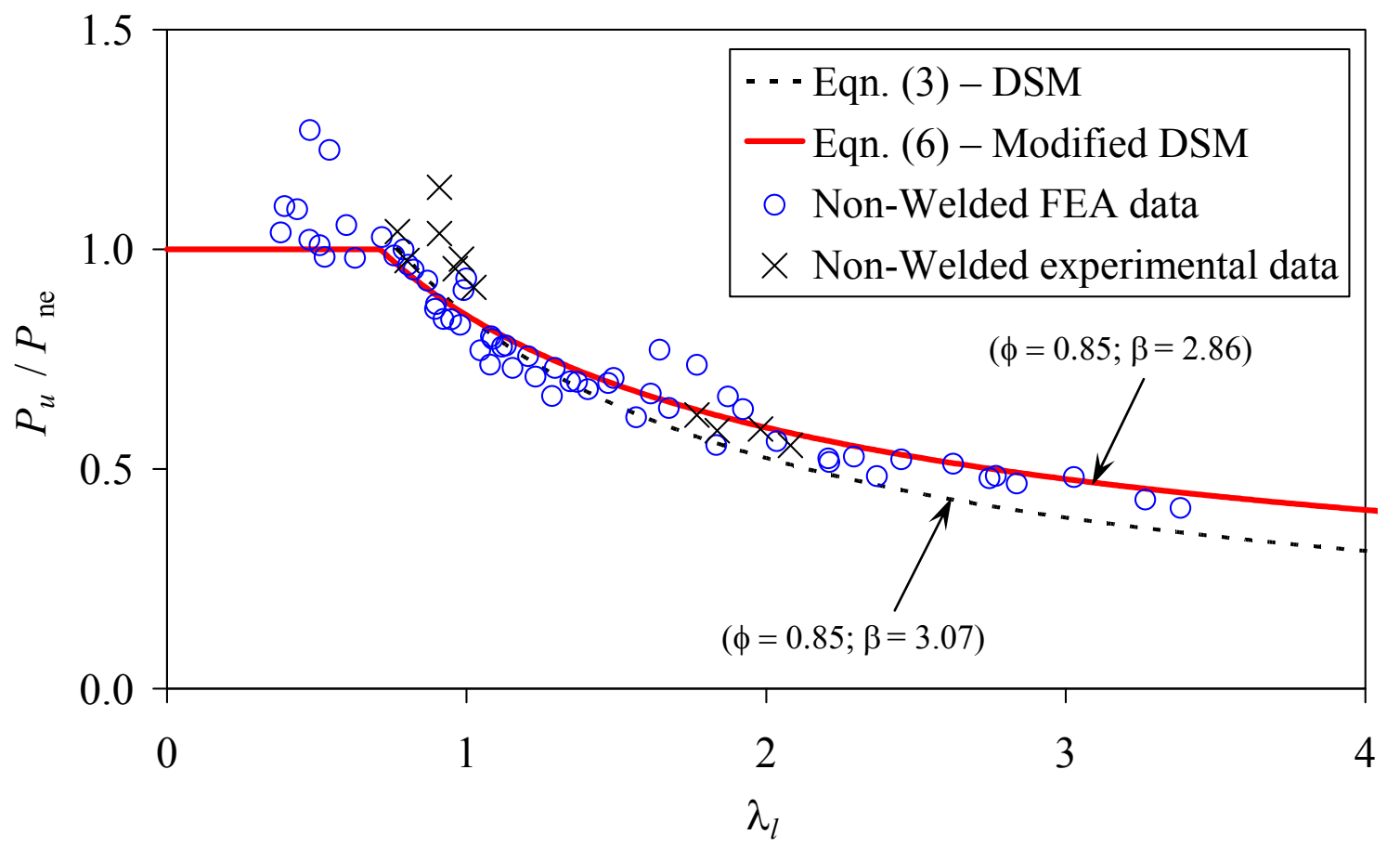

Figure 9. Comparison of FEA and Experimental Data with Direct Strength Curves for SHS and RHS Non-welded Columns

It is also shown that the current direct strength method is not suitable for the design of aluminum welded columns, as detailed in Zhu and Young [15]. Two design approaches were proposed for aluminum SHS and RHS columns with transverse welds at both ends of the columns (welded columns), as shown in Zhu and Young [15]. The two design approaches were also modified from the current direct strength method as well as the current nominal axial strength $\left(P_{\text {ne }}\right)$ equations for flexural buckling. The first approach adopts the non-welded material properties in calculating the welded column strength. The second approach adopts the welded material properties in calculating the welded column strength. Furthermore, design equation was also proposed based on the current direct strength method for aluminum alloy CHS welded columns, as presented by Zhu [8]. The design strengths calculated using the proposed design equations were compared with the column strengths obtained from the experimental investigation $[9,10]$ and numerical investigation $[8,15]$ for SHS, RHS and CHS columns. The reliability of the design rules was evaluated using reliability analysis. It is shown that the proposed design rules are accurate and reliable. 


\section{CONCLUSIONS}

The research program of the $\mathrm{PhD}$ thesis of the first author has been summarized. The program included experimental and numerical investigations as well as design of aluminum alloy structural members.

Tests were performed on aluminum alloy columns, beams and beam-columns of square, rectangular and circular hollow sections. Material properties of the test specimens were obtained from coupon tests. Local and overall geometric imperfections were measured. Test results were compared with the design strengths calculated using the current American, Australian/New Zealand and European specifications for aluminum structures. It is shown that the design strengths predicted by the three specifications are generally conservative.

A non-linear finite element model incorporating geometric imperfections and material non-linearity was developed for fixed-ended aluminum alloy non-welded and welded columns. The welded columns were modeled by dividing the column into different portions along the column length, so that the heat-affected zone softening at both ends of the welded columns was included in the simulation. The finite element model was verified against the test results. It is shown that the finite element model provides accurate predictions of the experimental ultimate loads and failure modes for both the non-welded and welded columns. Parametric study was conducted using the verified finite element model.

The effects of transverse welds on aluminum alloy columns of square and circular hollow sections have been investigated. The heat-affected zone softening factors obtained from the parametric study were compared with the corresponding values specified in the European Code for aluminum structures. It is shown that the values of the heat-affected zone softening factor specified in the European Code are generally conservative for the square and circular hollow section columns. The heat-affected zone softening factors have been proposed for square and circular hollow sections based on the results obtained from the parametric study. It is shown that the proposed heat-affected zone softening factors are in good agreement with the numerical results.

The column strengths were compared with the design strengths calculated using the current direct strength method that was developed for cold-formed steel members. It is shown that the direct strength method can be used for the design of aluminum alloy non-welded tubular columns. It is also shown that the current direct strength method is not suitable for the design of aluminum welded columns. Based on the data obtained from the experimental and numerical investigations, design rules modified from the direct strength method were proposed for aluminum non-welded and welded columns. Reliability analysis was performed to evaluate the reliability of the design rules. It is shown that the design strengths calculated using the proposed design rules are in good agreement with the experimental and numerical results. It is also shown that the proposed design rules are reliable.

\section{ACKNOWLEDGMENT}

The test specimens were sponsored by the Asia Aluminum Manufacturing Company. 


\section{REFERENCES}

[1] AA. Aluminum Design Manual, Washington, D.C.: The Aluminum Association, 2000.

[2] AS/NZS, Aluminum Structures Part 1: Limit State Design, Australian/New Zealand Standard AS/NZS 1664.1:1997. Sydney, Australia: Standards Australia, 1997.

[3] EC9, Eurocode 9: Design of Aluminum Structures - Part 1-1: General Rules - General Rules and Rules for Buildings, DD ENV 1999-1-1:2000, Final Draft Oct. 2000. European Committee for Standardization, 2000.

[4] Mazzolani, F.M., “Aluminum Alloy Structures”, 2nd Edition. London: E \& FN Spon; 1995.

[5] Kissell, J.R., Ferry, R.L., "Aluminum Structures - A Guide to their Specifications and Design", 2nd Edition, New York: John Wiley \& Sons, 2002.

[6] Sharp, M.L., "Behavior and Design of Aluminum Structures", New York: McGraw-Hill; 1993.

[7] Brungraber, R.J. and Clark, J.W., "Strength of Welded Aluminum Columns", Journal of Structural Division, ASCE, 1960.

[8] Zhu, J.H., "Behaviour and Design of Aluminum Alloy Structural Members", PhD Thesis, Department of Civil Engineering, The University of Hong Kong, Hong Kong; 2006.

[9] Zhu, J.H. and Young, B., "Tests and Design of Aluminum Alloy Compression Members", Journal of Structural Engineering, ASCE, 2006; Vol. 132, No. 7, pp 1096-1107.

[10] Zhu, J.H. and Young, B., "Experimental Investigation of Aluminum Alloy Circular Hollow Section Columns", Engineering Structures, 2006, Vol. 28, No. 2, pp. 207-215.

[11] Zhu, J.H. and Young, B., "Experimental Investigation of Aluminum Alloy Thin-walled Tubular Members in Combined Compression and Bending", Journal of Structural Engineering, ASCE, 2006; Vol. 132, No. 12, pp 1955-1966.

[12] Zhu, J.H. and Young, B., "Aluminum Alloy Circular Hollow Section Beam-columns", Thin-Walled Structures, 2006, Vol. 44, No. 2, pp. 131-140.

[13] ABAQUS Analysis User's Manual, Version 6.5, ABAQUS, Inc., 2004.

[14] Zhu, J.H. and Young, B., "Aluminum Alloy Tubular Columns - Part I: Finite Element Modeling and Test Verification", Thin-Walled Structures, 2006, Vol. 44, No. 9, pp. 961-968.

[15] Zhu, J.H. and Young, B., "Aluminum Alloy Tubular Columns - Part II: Parametric Study and Design using Direct Strength Method", Thin-Walled Structures, 2006, Vol. 44, No. 9, pp. 969-985.

[16] Zhu, J.H. and Young, B., "Effects of Transverse Welds on Aluminum Alloy Columns. Thin-Walled Structures", 2007, Vol. 45, No. 3, pp. 321-329.

[17] Galambos, T.V., "Guide to Stability Design Criteria for Metal Structures", 5th Edition, New York: John Wiley \& Sons, 1998.

[18] North American Specification for the Design of Cold-formed Steel Structural Members, American Iron and Steel Institute, Washington, D.C., 2001.

[19] Supplement to the North American Specification for the Design of Cold-formed Steel Structural Member, American Iron and Steel Institute, Washington, D.C., 2004. 